\title{
INBOUND MARKETING E CAMPANHAS PATROCINADAS: O USO DO FACEBOOK COMO FERRAMENTA DE VISIBILIDADE
}

\author{
OLIVEIRA, Daniella Ferreira ${ }^{1}$ \\ CIRIBELI, João Paulo ${ }^{1}$ \\ NAMORATO, Rafaela Martins ${ }^{1}$ \\ MENDES, Wanderson de Almeida ${ }^{2}$
}

\begin{abstract}
RESUMO: A competitividade no mercado exige, cada vez mais, estratégias empresariais eficientes e eficazes que buscam melhorar a divulgação dos produtos e serviços oferecidos pelas empresas. Desse modo, surge o Inbound Marketing como uma nova ferramenta mercadológica. Este estudo tem por objetivo analisar como o uso do Facebook influenciou na visibilidade da Faculdade Governado Ozanam Coelho - FAGOC, mais especificamente em relação às postagens patrocinadas no Facebook Ads. Quanto à classificação metodológica este estudo se classifica em aplicado, qualitativo, exploratório, descritivo, bibliográfico e estudo de caso intrínseco. Quanto aos procedimentos metodológicos e aos instrumentos de coleta de dados, utilizou-se da pesquisa embasada por dados secundários, através de pesquisa documental, junto ao Núcleo de Comunicação FAGOC e à página da Instituição de Ensino Superior no Facebook. Sobre a amostragem, foi realizada uma análise comparativa entre as três campanhas publicadas na página do Facebook da FAGOC durante o ano de 2016, de forma orgânica e patrocinada. Os dados foram analisados essencialmente de forma qualitativa, no entanto são apresentadas informações quantitativas de caráter comparativo. Com base nos resultados verificou-se um considerável aumento de visualizações, curtidas e cliques no site quando a postagem foi patrocinada, aumentado em média 8 vezes o número de visualizações de vídeo, e em 6 vezes o número de cliques direcionados para o site da instituição, ampliando dessa forma a visibilidade da faculdade na rede social e, na internet.
\end{abstract}

Palavras-chave: Marketing de Conteúdo. Inbound Marketing. FAGOC. Facebook.

SUMMARY: Competitiveness in the marketplace demands, increasingly, efficient and effective business strategies that seek to improve the dissemination of products and services offered by companies. In this way, Inbound Marketing emerges as a new marketing tool. This study aims to analyze how the use of Facebook influenced the visibility of FAGOC, more specifically in relation to Facebook Ads sponsored posts. As for the methodological classification, the present study is classified as applied, qualitative, exploratory, descriptive, bibliographical and intrinsic case study. As for the methodological procedures and the data collection instruments, the research was based on secondary data, through documentary research, with the FAGOC Communication Center and the Institution of Higher Education page on Facebook. About the sampling, a comparative analysis was carried out between the three campaigns published on the Facebook page of FAGOC during the year 2016, in an organic and sponsored way. The data were analyzed essentially qualitatively, however comparative quantitative information is presented. Based on the results, there was a considerable increase in views, tastings and clicks on the site when the post was sponsored, an average of 8 times the number of video view5s, and 6 times the number of clicks directed to the institution's website, thus increasing the visibility of the faculty in the social network and, on the Internet.

Keywords: Content Marketing. Inbound Marketing. FAGOC. Facebook.

\section{INTRODUÇÃO}

O desafio das empresas em sobreviverem e prosperarem financeiramente diante de um mercado competitivo, torna o papel do marketing fundamental para o alcance de tais objetivos (KOTLER;

\footnotetext{
${ }^{1}$ Faculdade Governador Ozanam CoelhoFAGOC.

${ }^{2}$ Universidade Federal de Viçosa
} 
KELLER, 2012). Desse modo, destaca-se o uso das mídias digitais em campanhas de comunicação e Marketing das empresas, que tem aumentado e se diversificado pelo uso de diversas ferramentas, como a integração da mobilidade e portabilidade de acesso à web e com a otimização dos sistemas de busca, instituindo novos pilares de comunicação integrada (OKADA; SOUZA, 2011).

Dentro desse contexto, uma das estratégias utilizadas atualmente para atrair potenciais clientes na internet é o Inbound Marketing, que são ações de Marketing direcionadas a um público específico a fim de ganhar o interesse dessas pessoas em vez de comprá-las. Apesar de as empresas ainda não utilizarem muito essa ferramenta, as mídias sociais são componentes fundamentais do Inbound Marketing, e bastante eficazes na propagação de uma determinada mensagem para um público específico, com custos relativamente baixos (VARANDA, 2010).

Segundo Torres (2010, p. 18), "o Marketing nas mídias sociais é o conjunto de ações de Marketing digital que visam criar relacionamento entre a empresa e o consumidor, para atrair a sua atenção e conquistar o consumidor online". Ao recorrer às redes sociais, as empresas têm acesso a veículos de comunicação que possibilitam a realização de ações com um menor custo, quando comparadas às campanhas realizadas através das mídias tradicionais. Além disso, eliminam os intermediários no processo de comunicação e intensificam o relacionamento com o público-alvo (ROMANO et al., 2014).

Em meio às diversas possibilidades de mídias sociais, está o Facebook, a maior rede social do mundo, e atualmente um dos principais canais para os sites institucionais, em que milhões de usuários acessam suas contas diariamente e compartilham seus conteúdos com o resto do mundo, sendo até mesmo, para diversas marcas, o terceiro sistema de busca principal, depois das ferramentas de pesquisa Google e Yahoo (BAREFOOT; SZABO, 2010; TOMAS; MESCHGRAHW; ALCANTARA, 2012).

Aproximadamente $48 \%$ dos brasileiros usam a internet, e o percentual de pessoas que a utiliza diariamente cresceu de 26\% na Pesquisa Brasileira de Mídia - PBM 2014 para 37\% na PBM 2015. O uso de dispositivos móveis (tablets e smartphones) como forma de acesso à internet compete com o uso através de computadores ou notebooks, $66 \%$ e $71 \%$, respectivamente. O uso das mídias sociais influencia esse resultado. Entre os internautas, 92\% são usuários das redes sociais, sendo as mais utilizadas o Facebook (83\%), o WhatsApp (58\%) e o Youtube (17\%) (SECRETARIA DE COMUNICAÇÃO SOCIAL DA PRESIDÊNCIA DA REPÚBLICA, 2014).

Diante à competitividade do mercado, em que as empresas buscam divulgação de seus produtos e serviços a fim de atrair clientes, têm-se o Facebook como ferramenta de marketing utilizado por diversas organizações com este fim. Nesse sentido, este estudo tem como objetivo mensurar em que medida o patrocínio na rede social Facebook amplia a visibilidade e divulgação da Faculdade Governador Ozanam Coelho - FAGOC.

Apesar de ser um tema recente, alguns pesquisadores abordaram o Inbound Marketing em seus estudos, como Patrutiu-Baltes (2016) que apontou sobre sua a importância, tendo como resultado a mudança do comportamento do consumidor devido ao avanço do uso da internet. Já Opreana e Vinerean (2015) propuseram examinar as estratégias online associadas ao Inbound Marketing, e seus achados apontaram que o marketing tradicional além de ser mais caro, é também ineficaz, e que o Inbound Marketing surgiu como uma alternativa melhor para as empresas de modo em geral.

Nesse contexto, esta pesquisa se diferencia das demais por avaliar empiricamente uma perspectiva prática de uma instituição de ensino, e por pesquisar a influência de uma mídia social eletrônica sobre a visão que as pessoas têm em relação a uma faculdade mineira, atuando como meio de divulgação do serviço prestado pela faculdade, justificando assim, este estudo. 
Em termos práticos o estudo ainda é justificável na medida em que se constitui de base para consulta de acadêmicos, profissionais da área e pesquisadores, além de fornecer subsídios à instituição analisada, para fins de tomada de decisão em futuras ações de impulsionamento nas redes sociais. Em termos teóricos, observa-se uma crescente, mas ainda insipiente literatura sobre inbound marketing e campanhas patrocinadas, nesta perspectiva o trabalho fomenta o aperfeiçoamento conceitual do termo inbound marketing, bem como sua distinção com termos tradicionais do marketing (outbound). Outro avanço teórico recai sobre os indicadores a serem analisados numa campanha em redes sociais, como alcance, curtidas, comentários, compartilhamentos, entre outros.

\section{REFERENCIAL TEÓRICO}

\section{Conceito de Inbound Marketing}

A principal função dos comerciantes é convencer as pessoas a comprarem seus produtos e serviços. Para isso, normalmente eles utilizam técnicas chamadas de Outbound, em que o comerciante vai atrás do cliente, utilizando um marketing ativo, considerado também como interruptivo, podendo ser visualizada em propagandas de TV e de rádios. Cansadas de serem interrompidas, as pessoas encontraram formas de se esquivar dos comerciantes, o que motivou os comerciantes a criarem uma nova forma de abordagem, o Inbound Marketing (HALLIGAN; SHAH, 2009).

Inbound Marketing ou Marketing de Conteúdo é uma forma de pensar relativamente nova, fundamentada na ideia de compartilhamento e criação de um conteúdo de qualidade direcionado para um público-alvo, utilizando táticas de Marketing online (HALLIGAN; SHAH, 2009; CARVALHO, 2013). Patrutiu-Baltes (2016, p. 62) considera o Inbound Marketing como "uma forma de marketing que requer uma segmentação muito cuidadosa do público e a comunicação personalizada com ele através de conteúdo de alta qualidade". Fishkin e Hogenhaven (2013) ainda completam dizendo que a técnica de Inbound marketing é um meio eficiente e eficaz de comercialização de produtos e serviços.

As ações de Inbound Marketing são direcionadas por meio de canais digitais, que originam informações e/ou recomendações como uma extensão do produto ou para aprofundar a relação com os consumidores (PEREZ; GOSLING; ANDRADE, 2014). Baseia-se em definir o público-alvo, estabelecer pontos de conexão, entregar valor e educar o cliente na forma de conteúdo em suas mais variadas formas, medindo cada etapa do relacionamento para mantê-lo sempre relevante para o consumidor (REZ; MORAES, 2013).

O Inbound Marketing, também conhecido como "novo Marketing", baseia em ganhar o interesse das pessoas em vez de comprá-las, diferenciando-se do Outbound Marketing, conhecido "velho Marketing", que usa qualquer tática de Marketing para ir até os potenciais clientes e "empurrar" a eles os produtos ou serviços (HALLIGAN; SHAH, 2009; CARVALHO, 2013; NOGUEIRA, 2014).

O "novo Marketing" apresenta diversas diferenças em relação ao "velho Marketing", entre elas pode-se citar as listadas no Quadro 1, a seguir. 
Quadro 1: Diferença entre Inbound Marketing e Outbound Marketing

\begin{tabular}{|l|l|}
\hline \multicolumn{1}{|c|}{ INBOUND MARKETING } & \multicolumn{1}{c|}{ OUTBOUND MARKETING } \\
\hline $\begin{array}{l}\text { Responsável por mais de } 90 \% \text { dos cliques na } \\
\text { web. }\end{array}$ & Responsável por apenas $10 \%$ dos cliques na web. \\
\hline Baixo custo médio para adquirir um novo clique. & Alto custo médio para adquirir um novo clique. \\
\hline Comunicação interativa em via dupla. & Comunicação é unidirecional. \\
\hline $\begin{array}{l}\text { Clientes vem até você através de ferramentas de } \\
\text { busca, referências e mídias sociais. }\end{array}$ & $\begin{array}{l}\text { Clientes são procurados, através de impressões, TV, } \\
\text { rádio, banner, anúncios, etc. }\end{array}$ \\
\hline Empresas fornecem valor. & $\begin{array}{l}\text { Empresas fornecem pouco ou nenhum valor } \\
\text { agregado. }\end{array}$ \\
\hline $\begin{array}{l}\text { Utilizam otimização de mecanismo de pesquisa } \\
\text { - SEO e listas de e-mails. }\end{array}$ & Spam ou listas de e-mails pagas ou alugadas. \\
\hline Boca-a-boca e Marketing viral. & Comentários Spam em blogs, sites e fóruns. \\
\hline Criação de conteúdo e Marketing. & Uso de banners e exposição de publicidade. \\
\hline Conteúdos de vídeo. & Publicidade em vídeo. \\
\hline
\end{tabular}

Fonte: Carvalho (2013).

O Inbound Marketing utiliza a internet como uma ferramenta, envolvendo comunicação, propaganda, publicidade e todos os termos e estratégias já conhecidos do Marketing tradicional (TORRES, 2009). O consumidor busca informações relevantes e úteis, por isso a importância do Marketing de conteúdo, considerado como a utilização do conteúdo a ponto de permitir que o consumidor possa encontrar, gostar e interagir com aquilo que está sendo divulgado (TORRES, 2009). Para o autor, não se devem disfarçar propagandas nem criar mensagens subliminares, mas sim usufruir a dinâmica da internet e se beneficiar dela, aproximando-se do consumidor.

Para atrair a atenção das pessoas, o Inbound Marketing usa sites, mídias sociais, blogs e táticas de SEO (otimização do conteúdo do seu site para mecanismos de buscas, como o Google) (MESQUITA, 2015). Ele é focado em gerar tráfego de visitantes que estão à procura de assuntos relacionados com o site que adota essa técnica, ou seja, essa estratégia de Marketing é focada em ser encontrado pelos consumidores (VARANDA, 2010).

Os profissionais de Marketing que potenciam o Marketing de Conteúdo criam vídeos relacionados aos interesses do consumidor, disponibilizam o conteúdo para os blogs, comunidades virtuais e sites, nos quais as pessoas interessadas podem se registrar, ler e subscrever. Esse conteúdo é o que atrai o públicoalvo para o site ou negócio (VARANDA, 2010).

O Inbound Marketing faz com que esse conteúdo seja de valor para que os clientes entrem em contato com a empresa. Seu principal objetivo é tornar a empresa tão atrativa para os clientes, de modo que sejam eles a entrarem em contato com a empresa (VARANDA, 2010). Na Figura 1, podem-se visualizar os seus três componentes chave. 
Figura 1: Componentes do Inbound Marketing

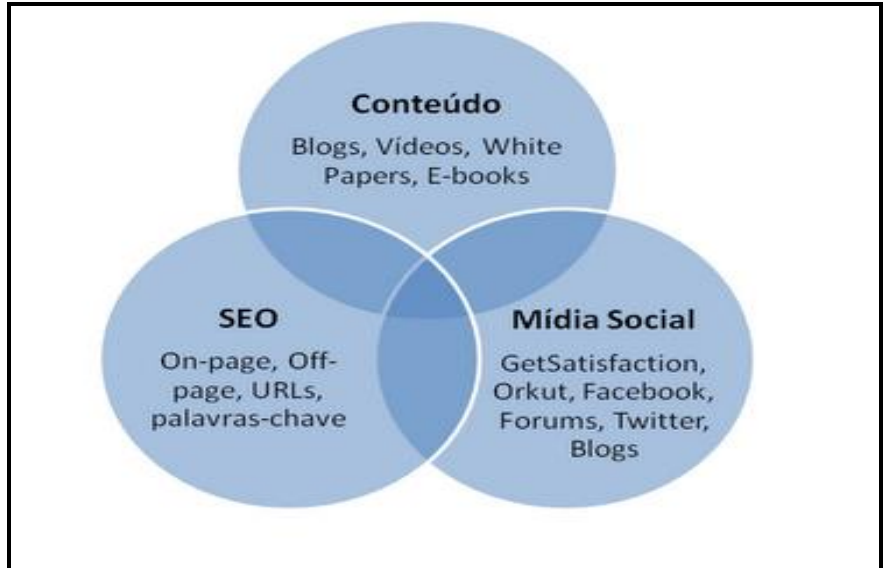

Fonte: Ribeiro (2011).

O primeiro componente é o Conteúdo, ou seja, as informações que atrai o público-alvo para determinado site (COSTA, 2013). Já a Otimização, junto dos mecanismos de busca (SEO), facilita que os clientes encontrem o conteúdo de um determinado site. É através do website e dos links que apontam para ele que se otimiza a classificação orgânica junto aos mecanismos de busca, onde a quase totalidade dos processos de compra se iniciam (COSTA, 2013; RIBEIRO 2011). Por fim, uma forte presença nas mídias sociais aumenta o alcance e o impacto do conteúdo apresentado por um website. No momento em que o conteúdo é partilhado e comentado através de diversas formas, tornar-se-á mais pertinente e relevante, com maior possibilidade de atrair clientes qualificados para o site, já que a área de atuação se torna mais abrangente. Conteúdos relevantes, fáceis de encontrar, aliados a uma presença ativa nas redes sociais, fazem com que a sua utilidade aumente substancialmente (COSTA, 2013).

A Figura 2 representa o processo de Inbound Marketing em cinco etapas principais: atrair tráfego; converter visitantes em leads ${ }^{3}$; converter leads em vendas; fidelizar os clientes e aumentar as margens; encantar seus clientes e transformá-los em promotores (PEÇANHA, 2015).

Figura 2: Fases do Inbound Marketing

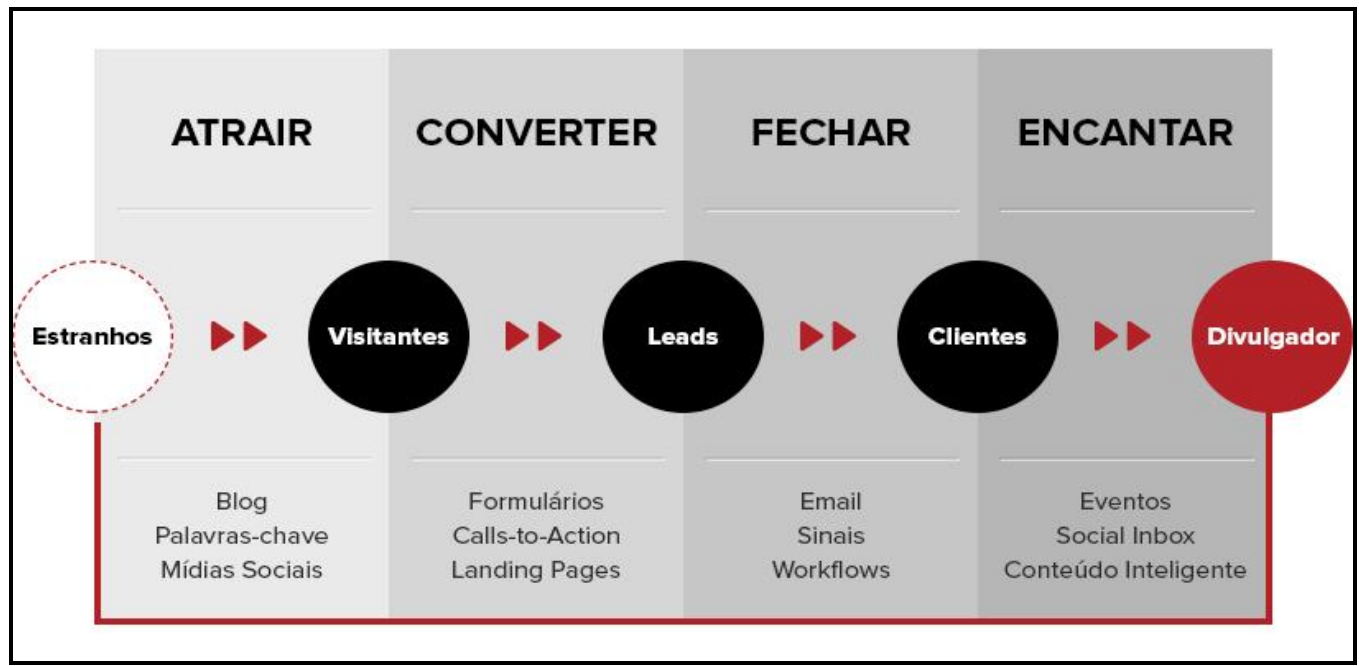

Fonte: Peçanha (2015), adaptada pelos autores.

\footnotetext{
${ }^{3}$ Visitante que mostrou interesse pelo produto ou serviço e se cadastrou para receber mais conteúdo (MESQUITA, 2015).
} 
Contudo, as etapas do Inbound Marketing, devem estar ligadas ao lugar, tempo e conteúdo, ou seja, quando se produz e se entrega o conteúdo certo, no momento e no local correto, as pessoas tendem a absorver melhor as informações e a ficar mais propensas a interagir. Por meio do Inbound Marketing, as marcas são encontradas mais facilmente na rede e os consumidores direcionados aos sites, através da geração de conteúdos que agreguem valor (PEÇANHA, 2015).

\section{Publicidade no Facebook}

Atualmente, as redes sociais são uma das várias táticas de Marketing de conteúdo existentes e amplamente utilizadas pelas pessoas (POLITI, 2013; OPREANA; VINEREAN, 2015; PATRUTIUBALTES, 2016). Uma pesquisa realizada por Politi (2013) sobre o uso de redes sociais em empresas no Brasil apontou que $97 \%$ das empresas que utilizam algum tipo de comunicação online possuem um perfil no Facebook. No entanto, apenas 3\% trabalham o fortalecimento da marca como prioridade.

Por meio das redes sociais, a comunicação organizacional amplia seu poder de segmentação. Através delas, é possível mapear as pessoas que mais se identificam com a marca e fazer ações direcionadas especificamente para elas, ampliando a liberdade criativa das campanhas e aumentando potencialmente sua assertividade (ROMANO et al., 2014).

Criado em 2004, atualmente, o Facebook é o maior site de redes sociais do mundo, contando com 1,55 bilhão de usuários, mais de 1,4 bilhão de usuários mensais, dos quais 92 milhões são brasileiros que acessam a plataforma todos os meses (o que corresponde a $45 \%$ de toda a população brasileira), e mais de 900 milhões usuários diários. São 2,1 milhões de pequenas e médias empresas que anunciam seus produtos e serviços na plataforma para impulsionar seus resultados de negócios (FACEBOOK, 2015; DEMARTINI, 2015; TORRES; BOARON; KOWALSKI, 2017). As redes sociais com os maiores números de usuários registrados durante o ano de 2017 podem ser visualizadas na Figura 3.

O Facebook se tornou um lugar com maior concentração do público-alvo. A presença de pessoas de todas as idades na rede social permite que os mais variados segmentos de negócio aproveitem seus recursos para conquistar seus objetivos de Marketing (FACEBOOK, 2016c; PORTO, 2014).

As páginas corporativas da rede social Facebook são chamadas de fanpages e objetivam a divulgação de profissionais, produtos, empresas, serviços, dentre outros. Podem ser criadas por qualquer usuário no Facebook e geralmente são direcionadas a algum tipo de conteúdo específico, possibilitando vantagens para as empresas que as utilizam, principalmente no que se refere à aproximação do seu público-alvo, permitindo maior contato e colaborando no processo de conhecimento de necessidades e expectativas dos consumidores (RECUERO; SOARES, 2013; NESPOLO et al., 2015). 
Figura 1: Número de usuários em redes sociais

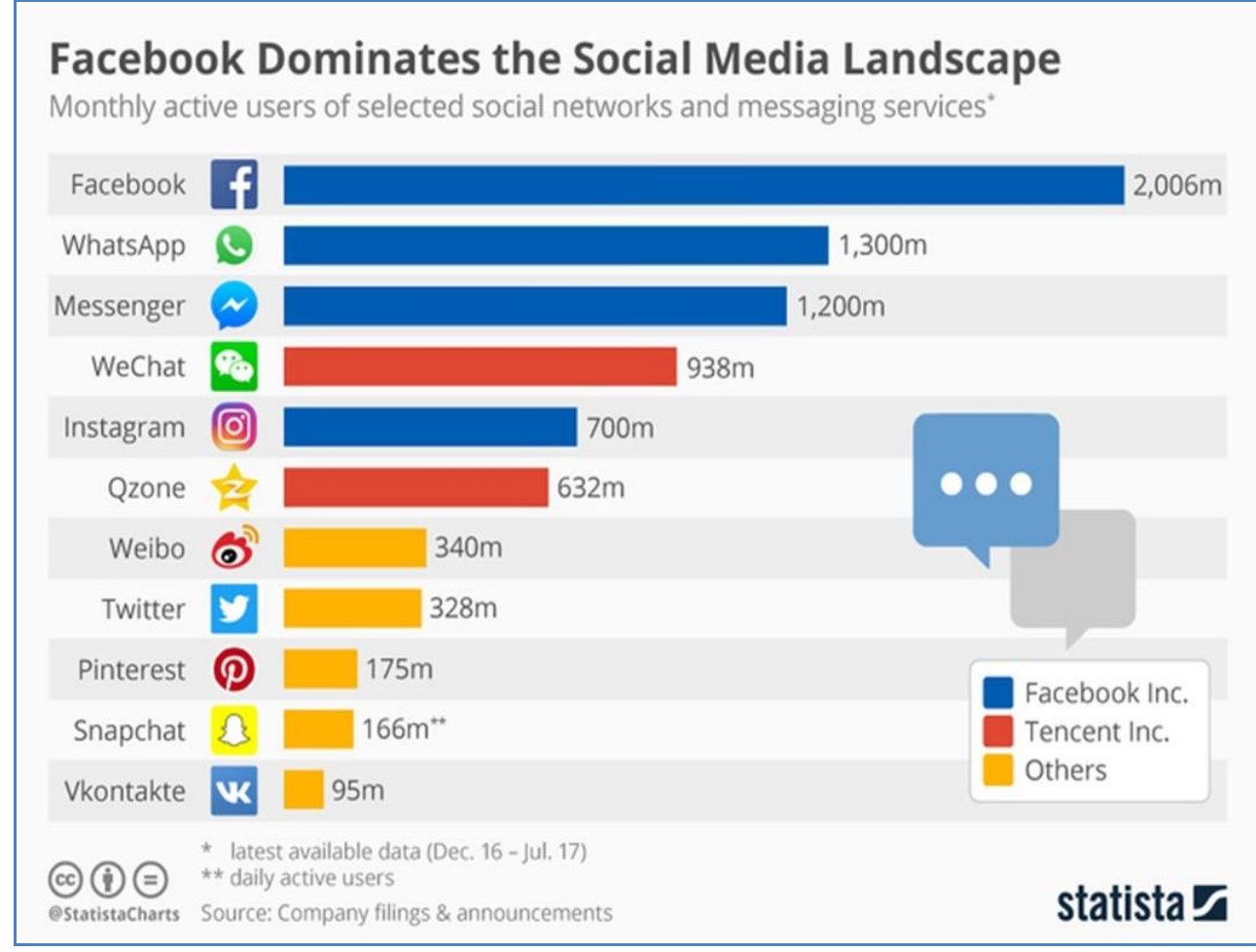

Fonte: Statista (2017).

Com o uso da fanpage Facebook, as empresas podem divulgar seus produtos, interagir com o cliente e realizar promoções exclusivas para os seus fãs (pessoas que utilizam a ferramenta curtir, específica desta rede social). Esse é um dos motivos que despertam, nos consumidores, o interesse em tornarem-se fãs da organização. Por outro lado, oportuniza à empresa aumentar a capacidade de divulgação de sua marca e seus produtos e/ou serviços (NESPOLO et al., 2015).

\section{Facebook Ads}

Com a chegada dos anúncios ao Facebook, em novembro de 2007, por meio da ferramenta Facebook Ads, abriu-se mais um caminho para quem deseja utilizar a mídia paga para promover seu negócio. O Facebook se torna cada vez mais um canal interessante para marcas de todos os portes (PORTO, 2014).

Além de oferecer diversos formatos e modelos de anúncios, como descrito no Quadro 2, o contexto social em que os anúncios estão inseridos no Facebook e o tempo de permanência dos usuários no site são um atrativo para os negócios (PORTO, 2014). As opções de contexto social, locais de exibição e recursos de segmentação são pontos chave dos anúncios do Facebook. A ativação dos anúncios pode ser direcionada a um público-alvo, definido através de informações como gênero, idade, local de trabalho, instrução, interesses e estado civil fornecidas pelos usuários ao efetuarem o cadastro no site. Ou seja, para delimitar quem deverá receber o anúncio, é necessário utilizar dados demográficos, de interesse ou de conexão (TESTON; SOARES, 2013; PORTO, 2014). 
Quadro 2: Locais de visualização dos anúncios do Facebook

\begin{tabular}{|l|l|}
\hline \multicolumn{1}{|c|}{ LOCAL } & \multicolumn{1}{c|}{ DESCRIÇÃO } \\
\hline Barra lateral direita & A posição mais popular de exibição de anúncios. \\
\hline Feed de notícias & $\begin{array}{l}\text { Anúncios também podem ser direcionados, para aparecerem no feed de notícias } \\
\text { dos usuários do Facebook. }\end{array}$ \\
\hline Mobile & $\begin{array}{l}\text { Usuários do Facebook em dispositivos móveis também podem ser impactados } \\
\text { por anúncios. }\end{array}$ \\
\hline Tela de logout & $\begin{array}{l}\text { Formato destinado a grandes anunciantes para exibir anúncios na tela de logout } \\
\text { do Facebook. }\end{array}$ \\
\hline
\end{tabular}

Fonte: Porto (2014).

Quando uma empresa veicula um anúncio no Facebook, participa do leilão de anúncios, no qual se escolhe um orçamento, que é o valor total que quer gastar, e todos os anúncios serão interrompidos automaticamente quando atingir esse valor (FACEBOOK, 2016d). Escolhe-se também o valor a ser gasto por dia com os anúncios e o período em que estará ativo. É possível escolher entre pagar por clique (CPC - custo por clique) ou por 1.000 anúncios (CPM - custo por mil impressões), sendo o primeiro indicado para empresas que querem converter cliques em vendas ou visitas a um site externo, e o segundo para empresas que querem que sua marca seja vista por muitas pessoas (TESTON; SOARES, 2013).

A facilidade de criação, o tamanho da base de usuários e as opções de segmentação permitem que o Facebook Ads seja uma opção considerável para quem quer investir em mídia paga (PORTO, 2014).

\section{METODOLOGIA}

Para o alcance do objetivo proposto, a pesquisa utilizou o Setor de Marketing da FAGOC como unidade empírica de análise, localizada na cidade de Ubá-MG. Referentemente à classificação metodológica, esta pesquisa, quanto a sua natureza, é classificada como aplicada, e, do ponto de vista do tratamento dos dados, é considerada como qualitativa.

Quanto a seu objetivo, a pesquisa se classifica como exploratória e descritiva. A pesquisa ainda pode ser classificada, quanto aos meios, como um estudo de caso intrínseco, no qual o pesquisador pretende obter uma melhor compreensão do próprio caso (STAKE, 2005).

A pesquisa foi embasada em dados secundários, por meio de análise em documentos eletrônicos, como relatórios do Núcleo de Comunicação FAGOC e do Facebook Ads durante os meses de outubro, novembro e dezembro de 2016. No ano de 2016 a Instituição de Ensino Superior realizou 392 postagens no Facebook, das quais apenas três foram patrocinadas. Realizou-se então um levantamento dos resultados das três campanhas publicadas de maneira orgânica e patrocinadas. Foram analisadas somente essas três campanhas, pois foram as únicas publicadas pela FAGOC de modo orgânico e patrocinado, possibilitando o comparativo dos resultados obtidos por elas. Os dados foram retirados do Facebook e do Facebook Ads, e feito prints desses documentos eletrônicos, para analisar os resultados gerados pelas publicações. Foi calculado o aumento percentual entre os resultados obtidos nas campanhas, verificando em que medida o patrocínio nessa rede social amplia a visibilidade da instituição.

As campanhas da faculdade são lançadas nas redes sociais pelo Núcleo de Comunicação FAGOC e pelo setor de Marketing, que trabalham em conjunto e são responsáveis pela assessoria de comunicação e publicidade da instituição nas redes sociais e fora delas. 
Para se chegar aos resultados propostos pela pesquisa, foi feito um comparativo das três campanhas publicadas na página do Facebook da FAGOC durante o ano de 2016, de forma orgânica e patrocinada. A FAGOC realizou apenas três campanhas publicadas no Facebook neste período pelo motivo de experiência estratégica, sendo avaliada sua continuação nos anos seguintes.

\section{RESULTADOS E DISCUSSÃO}

Atualmente a FAGOC está presente nas redes sociais com perfis ativos no Facebook, no Instagram e no Youtube. A instituição faz geralmente duas postagens diárias no Facebook e uma no Instagram. No Youtube, não tem uma programação fixa; posta-se somente quando há produção de vídeo pelo Núcleo de Comunicação FAGOC, ficando em torno de dez postagens por mês. Como visto nesta pesquisa, o Facebook e o Youtube são as redes sociais mais acessadas do mundo, o que demonstra o motivo de a FAGOC tê-las escolhido para aumentar sua visibilidade na internet.

Ao se fazer uma campanha no Facebook Ads, definem-se alguns pontos: o público-alvo, o objetivo da campanha, o posicionamento do anúncio, entre outros. Os resultados obtidos com a campanha "Reinauguração da Biblioteca Antônio Olinto" e o aumento percentual da campanha orgânica para a patrocinada podem ser visualizados na Tabela 1 . O vídeo teve por objetivo obter um maior número possível de visualizações. Outros objetivos podem ser definidos em uma campanha no Facebook Ads como curtidas na página, cliques no site, geração de leads, participação no evento, envolvimento com a publicação da página, entre outros (FACEBOOK, 2016a).

Tabela 1: Campanha "Reinauguração da Biblioteca Antônio Olinto" *

\begin{tabular}{lccc}
\hline & Resultado Orgânico & Resultado Pago & Aumento (\%) \\
\hline Alcance & 10.913 & 59.532 & 445,51 \\
\hline Curtidas & 47 & 177 & 276,60 \\
\hline Comentários & 5 & 8 & 60 \\
\hline Compartilhamentos & 20 & 6 & -70 \\
\hline Visualizações & 2.214 & 32 & 622,67 \\
\hline Curtidas na Página & Não informado & & - \\
\hline
\end{tabular}

*Custo da postagem patrocinada: $\mathrm{R} \$ 150,00$.

Fonte: dados da pesquisa.

Essa campanha (Figura 4) foi publicada, de forma orgânica, no dia 1 de abril de 2016 e, de forma patrocinada, de 4 a 19 de abril de 2016. Percebe-se que houve um significativo aumento de visualizações do vídeo quando a campanha foi patrocinada, cerca de $600 \%$ a mais do que o resultado orgânico obtido. 
Figura 4: Campanha "Reinauguração da Biblioteca Antônio Olinto"

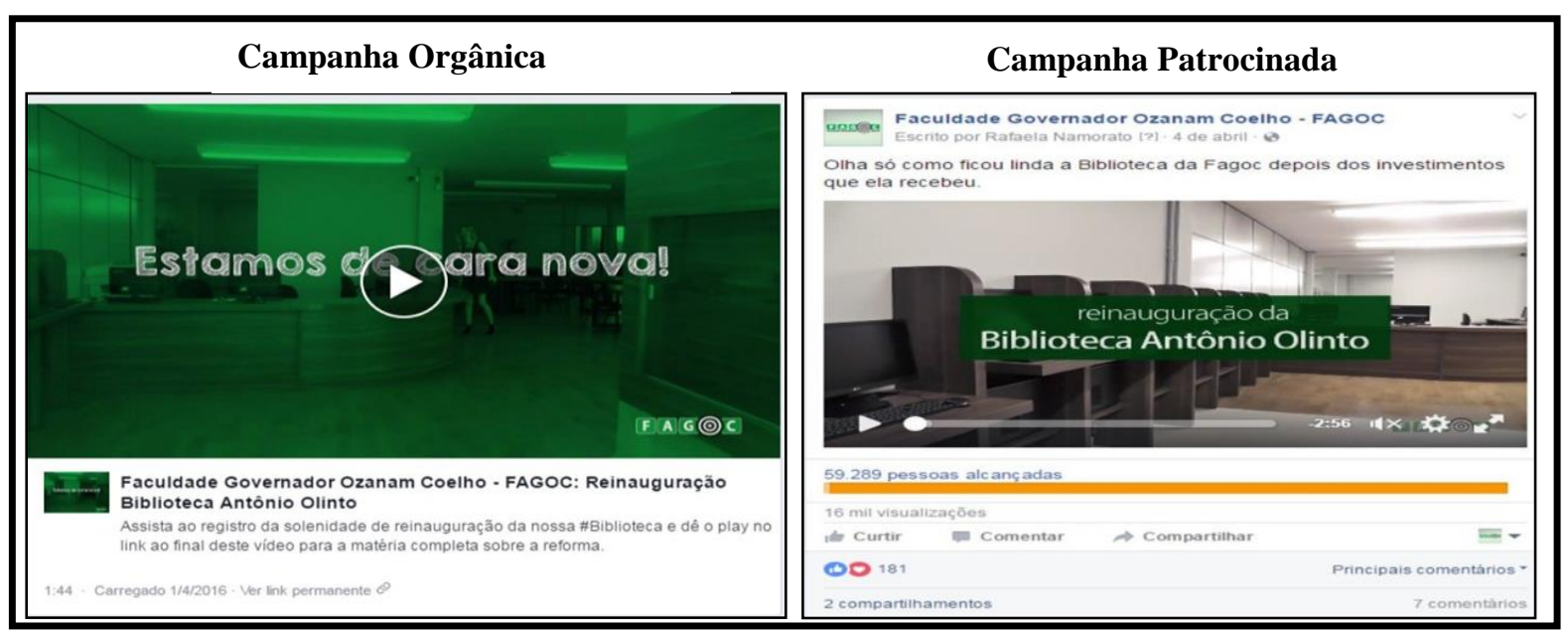

Fonte: dados da pesquisa.

O número de pessoas alcançadas com o anúncio, e o número de curtidas também tiveram uma grande diferença nas duas publicações, sendo que o alcance foi aproximadamente 5,45 vezes maior e o número de curtidas quase quadriplicou quando o anuncio foi patrocinado. Tais resultados corroboram a pesquisa de Opreana e Vinerean (2015), apontando a eficácia como um dos pontos positivos do Inbound Marketing.

$\mathrm{Na}$ Tabela 2, são apresentados os resultados orgânicos e pagos gerados com a campanha de lançamento "\#FalaDireito", cujo objetivo também foram as visualizações de vídeo. A campanha foi publicada no Facebook, de maneira orgânica, no dia 30 de março de 2016 e, de forma patrocinada, entre 1 de abril e 1 de maio de 2016, como demonstrada na Figura 5.

Tabela 2: Campanha de lançamento "\#FalaDireito" *

\begin{tabular}{lccc}
\hline & Resultado Orgânico & Resultado Pago & Aumento (\%) \\
\hline Alcance & 8.422 & 41.560 & 393,47 \\
\hline Curtidas & 47 & 160 & 240,43 \\
\hline Comentários & 1 & 3 & 200 \\
\hline Compartilhamentos & 22 & 8 & $-63,64$ \\
\hline Visualizações & 1.356 & 14.000 & 932,45 \\
\hline Curtidas na Página & Não informado & 42 & -
\end{tabular}

*Custo da postagem patrocinada: $\mathrm{R} \$ 200,00$.

Fonte: dados da pesquisa.

O número de visualizações obtidas com a campanha patrocinada foi bem maior (acima de 900\%) que os resultados orgânicos obtidos. Observa-se, porém, que o número de compartilhamentos do post, assim como na campanha "Reinauguração da Biblioteca Antônio Olinto", foi menor quando a campanha foi patrocinada. Esse resultado se deve ao fato de as pessoas alcançadas organicamente pelo anúncio serem mais próximas da instituição, como professores, alunos, entre outros. Essas pessoas geralmente são incentivadas a curtir e compartilhar os posts, por já conhecerem a faculdade e fazerem parte dela. 
Figura 5: Campanha "Lançamento \#FalaDireito

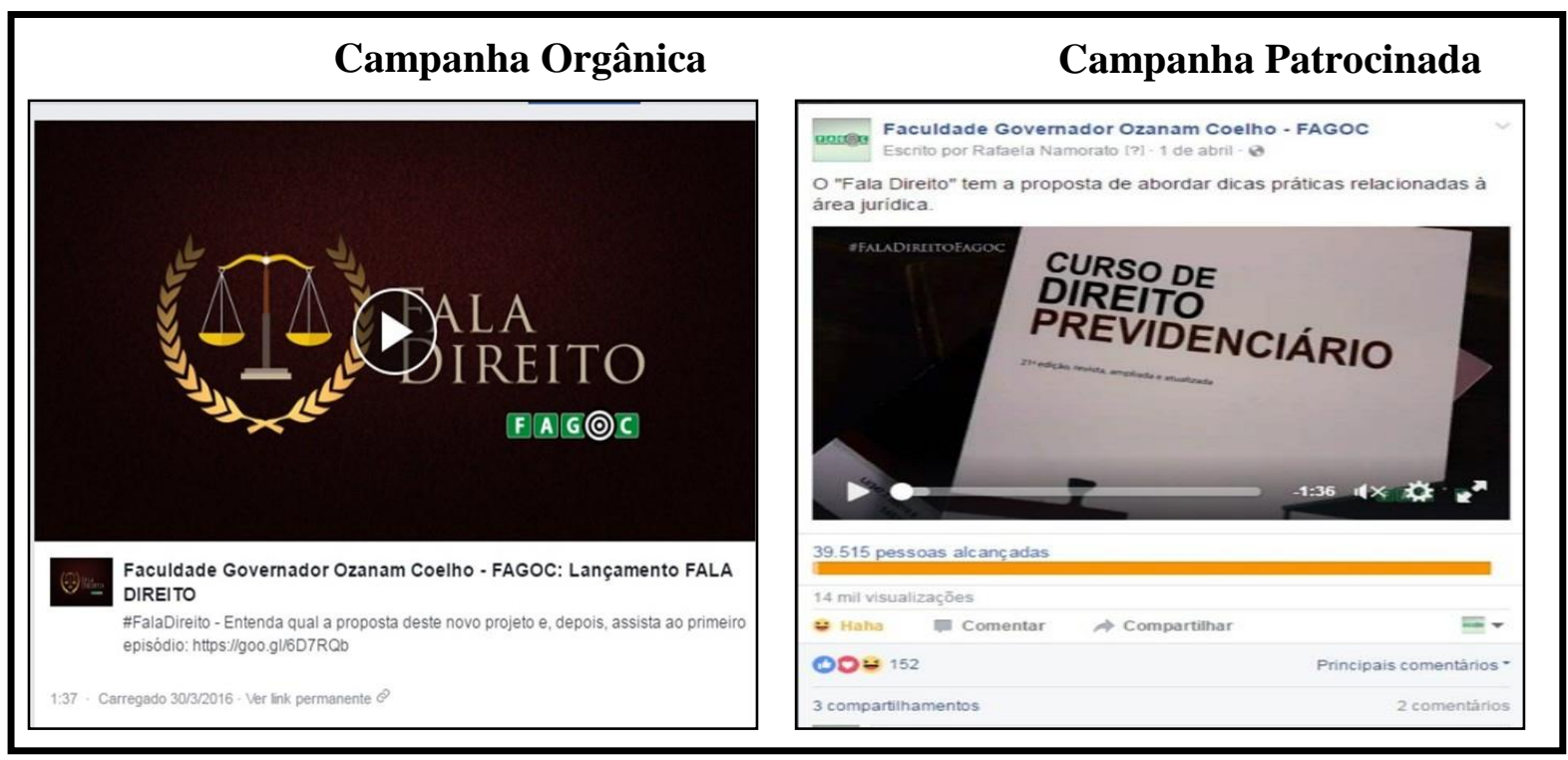

Fonte: dados da pesquisa.

Um bom resultado orgânico se deve também às ações de Marketing desenvolvidas pela empresa, que devem ser alinhadas com o comportamento do consumidor. Para serem efetivas, precisam conhecer profundamente os públicos que se relacionam com a marca ou empresa, ter a habilidade de fazer mapeamentos sociais e avançar no grau do relacionamento cada vez que é feita uma interação (GABRIEL, 2010). A uso do Inbound Marketing pela FAGOC, aliado às postagens patrocinadas, faz os resultados da página da instituição serem cada vez melhores.

O objetivo da campanha "Vestibular de Medicina 2017.1", apresentado na Tabela 3, foi cliques no site. Quando se define esse objetivo, a intenção é obter o maior número possível de cliques em um link que redireciona para o site na instituição. A campanha foi publicada de modo orgânico no dia 22 de julho de 2016 e de forma patrocinada entre os dias 28 de julho a 31 de agosto de 2016 conforme demonstrada na Figura 6.

Tabela 3: Campanha "Vestibular de Medicina 2017.1" *

\begin{tabular}{lccc}
\hline & Resultado Orgânico & Resultado Pago & Aumento (\%) \\
\hline Alcance & 1.300 & 36.183 & $2.683,31$ \\
\hline Curtidas & 17 & 144 & 747,06 \\
\hline Comentários & 5 & 21 & 320 \\
\hline Compartilhamentos & 5 & 10 & 100 \\
\hline Cliques & 60 & 341 & 468,33 \\
\hline Curtidas na Página & Não informado & 15 & - \\
\hline
\end{tabular}

*Custo da postagem patrocinada: $\mathrm{R} \$ 350,00$.

Fonte: dados da pesquisa.

Chama-se atenção para o número de pessoas alcançadas pela postagem patrocinada, que foi quase $2.700 \%$ maior que o alcance orgânico, ou seja, alcançou aproximadamente 27 vezes mais pessoas. Isso se deve principalmente a segmentação definida para a publicação, ou seja, quanto maior o público alvo escolhido, maior o número de pessoas alcançadas pelo anúncio (KOTLER; KELLER, 2012). 
Porém ao escolher um público pequeno e específico o anúncio obterá um desempenho melhor, se for exibido para as pessoas com maior probabilidade de se interessarem pelo produto ou serviço oferecido pela empresa. Quando o conjunto de anúncios é voltado para grupos menores e específicos de pessoas de uma vez, pode-se personalizar as imagens e textos para que eles chamem mais a atenção do público que está tentando alcançar (FACEBOOK, 2016b).

O número de cliques no site da FAGOC foi cerca de 6 vezes maior quando a campanha foi patrocinada no Facebook Ads, totalizando 401 cliques no site através das duas campanhas. Diferentemente das outras campanhas analisadas, esta apresentou um maior número de compartilhamentos quando foi patrocinada. Isso se deve ao maior número de pessoas alcançadas, que foi bem significativo, e que gostaram da campanha e a compartilhou.

Figura 6: Campanha "Vestibular de Medicina 2017-1"

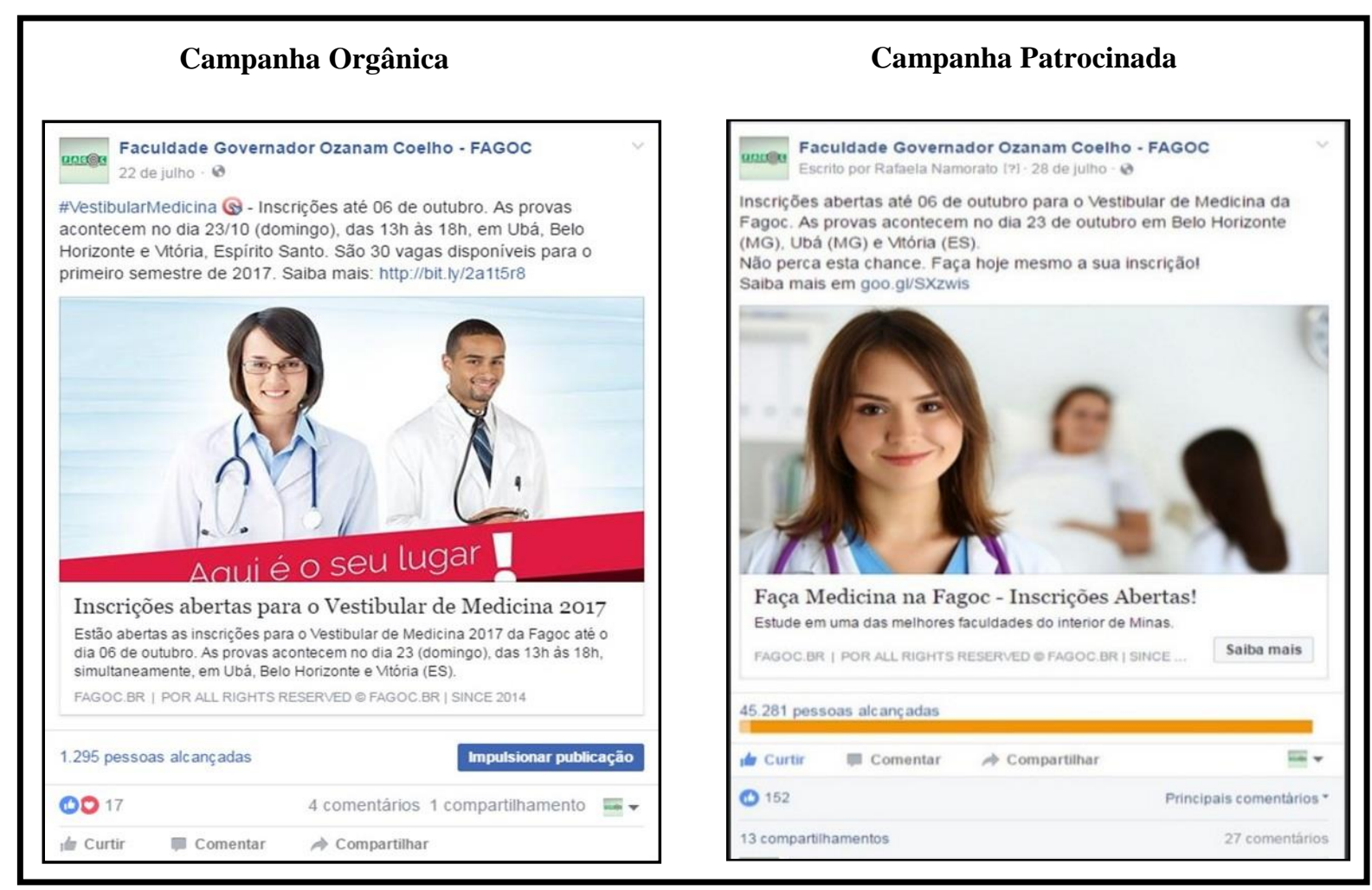

Fonte: dados da pesquisa.

O conteúdo de qualidade e engajamento na página são muito importantes para atingir o público e aumentar o compartilhamento do conteúdo, gerando até mesmo o efeito viral, e alcançando mais pessoas de forma orgânica e gratuita (PORTO, 2012).

Para Patrutiu-Baltes (2016), o Inbound Marketing tem sido cada vez mais importante, acompanhando as mudanças de comportamento dos consumidores, se tornando fundamental para o alcance dos objetivos das organizações.

\section{CONSIDERAÇÕES FINAIS}

O objetivo deste estudo foi de avaliar a visibilidade e divulgação da FAGOC por meio da utilização do Facebook como ferramenta de marketing. 
Comparando-se as três campanhas e calculando o aumento percentual entre os resultados obtidos, verificou-se um considerável aumento de visualizações, curtidas e cliques em postagens patrocinadas. Isso se deve ao maior número de pessoas alcançadas pelo anúncio.

Entretanto, nem sempre o número de compartilhamentos do post é maior quando a campanha é patrocinada, pois, apesar do alcance ser maior, muitas pessoas atingidas pela campanha não são o público alvo da faculdade. Assim, os resultados orgânicos acabam sendo melhores por alcançar pessoas próximas à instituição, como alunos e professores, que geralmente são estimulados a curtir e compartilhar os posts.

De maneira geral, o patrocínio no Facebook gera resultados satisfatórios para a faculdade, aumentando em média 8 vezes o número de visualizações de vídeo, e 6 vezes o número de cliques direcionados para o site da instituição, ampliando sua visibilidade na rede social e na internet.

Sobre as implicações práticas, a Instituição de Ensino Superior em estudo pode, a partir das informações levantadas e tabuladas, melhorar seu processo decisório em termos de investir ou não no impulsionamento de posts em redes sociais, bem como, analisar de forma comparativa o grau de eficácia de seus patrocínios. Nesta perspectiva a acurácia da tomada de decisão se torna maior.

Dentre as principais limitações para a realização da pesquisa, pode-se destacar o número reduzido de livros, artigos e estudos na área de considerável relevância acadêmica, pelo fato de as redes sociais e o Marketing na internet serem assuntos novos e estarem em constante mudança. Além disso, dentre as limitações, tem-se o número reduzido de postagens. Como só haviam três campanhas postadas na página do Facebook da faculdade, de forma orgânica e patrocinada, para se fazer o comparativo, os resultados encontrados não podem ser generalizados, mas são consideráveis e já dão uma base do alcance que se tem ao patrocinar uma campanha.

Deve-se levar em consideração também que o gasto ao patrocinar campanhas no Facebook Ads é relativamente baixo, comparado ao número de pessoas que são alcançadas e os benefícios para a instituição. Em média, a FAGOC gasta R\$ 200,00 em uma postagem patrocinada no Facebook, dependendo do objetivo da campanha, tempo de publicação, público alvo definido, entre outros, e a sua visibilidade é consideravelmente aumentada nessa rede social.

Este estudo contribui teoricamente por abordar sobre um tema ainda pouco estudado, porém bastante importante na área do marketing, buscando refletir sobre a mudança da estratégia de divulgação dos serviços e produtos, além de apresentar esta ferramenta para aqueles que ainda não conhecem, ou que possuem dúvidas em adotar ou não tal estratégia.

Para estudos futuros, propõe-se analisar os impactos dos posts nas diferentes segmentações do público-alvo, de forma a observar o comportamento das variáveis em cada grupo; bem como comparar os resultados pagos e os resultados orgânicos em diferentes ramos de atividades, como lazer, turismo, educação, saúde, etc.

\section{REFERÊNCIAS}

BAREFOOT, D.; SZABO, J. Manual de Marketing nas mídias sociais. São Paulo: Novatec, 2010.

CARVALHO, H. Inbound Marketing: a estratégia que está mudando a comunicação nos negócios. Viver de Blog, 29 set. 2013. Disponível em: <https://viverdeblog.com/inbound-Marketing/>. Acesso em: 27 mar. 2016.

COSTA, A. C. F. F. Impacto das redes sociais no Marketing. Coimbra, 2013. 
DEMARTINI, M. Facebook, WhatsApp e Instagram estão dominando o mundo. Exame, 5 nov. 2015. Disponível em: <http://exame.abril.com.br/tecnologia/noticias/facebook-domina-o-mundo-com-1-5bilhao-de-usuarios-mensais>. Acesso em: 28 mar. 2016.

FACEBOOK. Anúncios do Facebook. Facebook para empresas, 2016a. Disponível em: <https://ptbr.facebook.com/business/products/ads>. Acesso em: 20 mar. 2016.

. Como comprar anúncios do Facebook. Facebook para empresas, 2016d. Disponível em: $\langle$ https://pt-br.facebook.com/business/learn/how-much-facebook-ads-cost/>. Acesso em: 28 mar. 2016.

. Direcionamento Principal. Facebook para empresas, 2016b. Disponível em: <https://www.facebook.com/business/help/633474486707199>. Acesso em: 06 set. 2016.

Sobre os objetivos de publicidade. Facebook para empresas, 2016c. Disponível em: <https://www.facebook.com/business/help/517257078367892>. Acesso em: 29 ago. 2016.

. $45 \%$ da população brasileira acessa o Facebook mensalmente. Facebook para empresas, 2015. Disponível em: <https://pt-br.facebook.com/business/news/BR-45-da-populacao-brasileira-acessao-Facebook-pelo-menos-uma-vez-ao-mes >. Acesso em: 28 mar. 2016.

FISHKIN, R.; HOGENHAVEN, T. Inbound Marketing and SEO: Insights from the Moz Blog. Estados Unidos: John Wiley \& Sons, Inc., 2013.

GABRIEL, M. Marketing na era digital. São Paulo: Novatec, 2010.

HALLIGAN, B.; SHAH, D. Inbound marketing: get found using Google, social media, and blogs. Estados Unidos: John Wiley \& Sons Inc., 2009.

KOTLER, P.; KELLER, K. L. Marketing management. 14. ed. New Jersey: Prentice Hall, 2012.

MESQUITA, R. O guia definitivo do Inbound Marketing. Rock Content, Endeavor, Webinsider, 2015. Disponível em: <http://Marketingdeconteudo.com/guia-definitivo-do-inboundMarketing/>. Acesso em: 6 mar. 2016.

NESPOLO, D. et al. Comportamento do consumidor: fatores que influenciam o consumo virtual nas redes sociais. Rev. Ciênc. Admin., Fortaleza, v. 21, n. 1, p 288-316, jan./jun. 2015.

NOGUEIRA, J. O que é inbound Marketing? Administradores, ago. 2014. Disponível em:

<http://www.administradores.com.br/artigos/marketing/o-que-e-inbound-marketing/79999/>. Acesso em: 20 mar. 2016.

OKADA, S. I.; SOUZA, E. M. S. Estratégias de Marketing digital na era da busca. REMark - Revista Brasileira de Marketing, São Paulo, v. 10, n. 1, p 46-72, jan.-abr. 2011.

OPREANA, A.; VINEREAN, S. A New Development in Online Marketing: Introducing Digital Inbound Marketing. Expert Journal of Marketing, v. 3, n. 1, p. 29-34, 2015.

PATRUTIU-BALTES, L. Inbound Marketing - the most important digital marketing strategy. Bulletin of the Transilvania University of Brasov, Transilvânia, v. 9, n. 2, p. 61-68, 2016.

PEÇANHA, V. O que é inbound Marketing? Marketing de conteúdo, 14 jan. 2015. Disponível em: <http://Marketingdeconteudo.com/o-que-e-inbound-Marketing/>. Acesso em: 20 nov. 2018.

PEREZ, N. R.; GOSLING, M. S.; ANDRADE, M. A. M. Uma análise do Marketing de conteúdo da Coca-Cola no Facebook e sua relação com a percepção da imagem da marca perante seus consumidores.

Revista Cereus, UnirG, Gurupi-TO, v. 6, n. 3, set./dez. 2014.

Nucleus,v.15,n.2,out.2018 
POLITI, C. Content Marketing: o conteúdo que gera resultados. São Paulo: Bookess, 2013.

PORTO, C. Facebook Marketing. São Paulo: Novatec, 2014.

PORTO, C. Posts patrocinados: mais visibilidade para o conteúdo na sua fanpage. Camila Porto, 30 mai. 2012. Disponível em: 〈http://www.camilaporto.com.br/2012/05/30/posts-patrocinados-mais-visibilidadepara-o-conteudo-na-sua-fan-page/>. Acesso em: 20 nov. 2018.

RECUERO, R.; SOARES, P. Violência simbólica e redes sociais no facebook: o caso da fanpage "diva depressão". Galáxia, São Paulo, Online, n. 26, p. 239-254, dez. 2013.

REZ, R.; MORAES, A. 100 frases para aprender Marketing de conteúdo. Marketing de Conteúdo, 2013.

RIBEIRO, M. B. O que é inbound Marketing. Jornal do empreendedor, 2011. Disponível em:

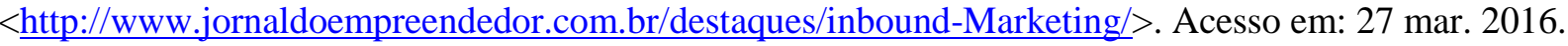

ROMANO, F. et al. O impacto das mídias sociais digitais na comunicação organizacional das empresas.

Future Studies Research Journal, São Paulo, v.6, n.1, p. 53-82, jan./jun. 2014.

SECRETARIA DE COMUNICAÇÃO SOCIAL DA PRESIDÊNCIA DA REPÚBLICA. Pesquisa brasileira de mídia 2015 - hábitos de consumo de mídia pela população brasileira. Brasília: Secom, 2014.

STAKE, R. Case Studies. In: DENZIN, N.; LINCOLN, T. Handbook of qualitative research. London: Sage, 2005.

STATISTA. Social Media Statistics \& Facts, 2017. Disponível em:

<https://www.statista.com/topics/1164/social-networks/> Acesso em: 22 nov. 2018.

TESTON, F. M.; SOARES, J. Z. Promoção para o comércio eletrônico: um estudo de caso sobre as ferramentas de aplicação da promoção no meio digital. Revista Técnico Científica do IF-SC. Santa Catarina, v. 2, n. 2 - II SICT-Sul, p. 181-191, 2013.

TOMAS, R. N.; MESCHGRAHW, R. P.; ALCANTARA, R. L. C. As redes sociais e o comportamento de compra do consumidor: o reinado do "boca-a-boca" está de volta? REMark - Revista Brasileira de Marketing, São Paulo, v.11, n. 2, p. 120-147, maio-ago. 2012.

TORRES, C. A bíblia do Marketing digital. São Paulo: Novatec, 2009.

Guia prático de Marketing na internet para pequenas empresas. E-Book, 2010.

TORRES, P. L.; BOARON, D. C.; KOWALSKI, R. P. G. Exposição fotográfica e uso do Facebook para fins educacionais. Holos, Natal, v. 1, p. 415-428, 2017.

VARANDA, L.I.A. Inbound Marketing: estudo sobre a percepção da credibilidade da fonte em comunidades online. Lisboa: ISCTE, 2010. Dissertação de mestrado. Disponível em

<http://hdl.handle.net/10071/3269>. Acesso em: 21 nov. 2018. 